\title{
A Non Web-Based Rainfall Information System for South Western Nigeria
}

\author{
Taofik O. Dauda ${ }^{1}$, Vincent A. Adeyemi ${ }^{2}$, Nurain A. Akintoye ${ }^{1}$, Bose O. Lawal ${ }^{1}$ \\ ${ }^{1}$ Institute of Agricultural Research and Training, Obafemi Awolowo University, \\ Ibadan, Nigeria \\ ${ }^{2}$ Federal College of Animal Health and Production Technology, Ibadan, Nigeria \\ E-mail: taofikdaud@yahoo.com \\ Received February 9, 2011; revised April 6, 2011; accepted June 30, 2011
}

\begin{abstract}
A non web-based rainfall data base of the South Western Nigeria was designed with the objective of providing user friendly source of data for the region. The study used the rainfall data obtained from the Institute of Agricultural Research and Training, Ibadan and it covers from year 1985 to 2007. The study uses Microsoft Access (2003) for data base creation as well as Visual Basic 6.0 (VB 6.0) for interface creation. The program developed could dynamically accommodate regular and new user of the data and could be upgraded for regular update of the data. The results of the programme evaluation showed that the data obtained from the database and the manual ones are the same.
\end{abstract}

Keywords: Database, Interface, Information System, Query, Rainfall

\section{Introduction}

Water is a precious commodity to agriculture in south western Nigeria. Its availability to plant through rainfall have been unstable in terms of distribution. Rainfall distribution model's prediction is thus challenging and requires data collected over a long period of time. Rainfall data for South Western Nigeria exist but not in an easily accessible form. Many organizations have extensively collected daily rainfall data prior to this study and are usually stored/recorded in sheets or log books. The shortcoming of this form of database is that it is prone to destruction by rain, fire and other disaster. Meanwhile back up copy are not easy to come by. Database is defined as a program that stores body of information in a form that makes its query management and design by different users as easy as possible [1] and [2]. It is an integrated collection of logically related records or files consolidated into a common pool that provides data for one or more multiple uses. Its use arises from the need to assess data promptly and in a retrievable way. Database keeps data in a window friendly environment and allows visitors to carry out some restricted use of the data. A Database Management System (DBMS) is a set of computer programs that controls the creation, maintenance, and the use of the database with computer as a platform or of an or- ganization and its end users [3]. According to [4], database, often abbreviated DB as a collection of information organized in such a way that a computer program can quickly select desired pieces of data. Database can be thought as an electronic filing system. There exist arrays of works on database and include, [5-7] and [2,8]. These works notwithstanding, rainfall data of the South western Nigeria were known to exist in white and black and little or no work on database of this region of the country is known to be available. This work is therefore justified from the need to create a database for the rainfall data of the selected areas. It is important in the provision of prompt and easy access to the data. It also provides a query platform for point or interval/ranged data. Information system therefore replaces the old paper work on rainfall data which makes data query, retrieval and management cumbersome. Rainfall data collection is a continuum which consequently prompts frequent updating of the data base. This is easily accomplished in an information system process. Rainfall database have been chosen in preference to other weather indices because it represents the major determinants of several other indices. Also, rainfall data of all the study areas are complete for the period under study. The objective of this work is therefore to develop/create a non web-based rainfall database of the South west Nigeria and to evaluate the created database 
for efficiency.

\section{Materials and Methods}

Data for this project was obtained from the data bank of the Institute of Agricultural Research and Training, Ibadan. These data include, rainfall, minimum and maximum temperature, dry and wet bulb thermometer reading, earth temperature (at $10 \mathrm{~cm}, 20 \mathrm{~cm}$ and $30 \mathrm{~cm}$ ) for Ibadan and rainfall for all other outstations (Ilora, Ikenne, Balla and Orin Ekiti). These areas cut across different vegetation gradient of the South west (Figure 1). Microsoft access (version 2003) was used for data storage while V-Basic was used to create the information system interface. Also included in the program is the computation of some selected descriptive statistics (like mean and variance). Mean and variance were given as,

$\bar{x}=\frac{1}{n} \sum_{i=1}^{n} x_{i}$ and $\sigma^{2}=\frac{1}{n-1} \sum_{i=1}^{n}\left(x_{i}-\bar{x}\right)^{2}$ respectively.

The program was evaluated through some selected query and outputs were compared with ordinary/raw data.

\section{Results}

Information system with the following components was evolved.

\subsection{Splash Screen}

This is the first window of the interface program. It consists of a screen showing the picture of the Institute at the background (Figure 2). It consists of two arrows in opposite direction: forward direction indicates movement to the next stage while the backward direction is for the premature quitting of the application.

\subsection{Welcome Interface}

Following the forward direction arrow on the splash screen leads to the Welcome page. This interface contains welcome information and few backgrounds about the information system as well as various actions the user might want to perform (Figure 3).

Four options are available here: the user can choose to

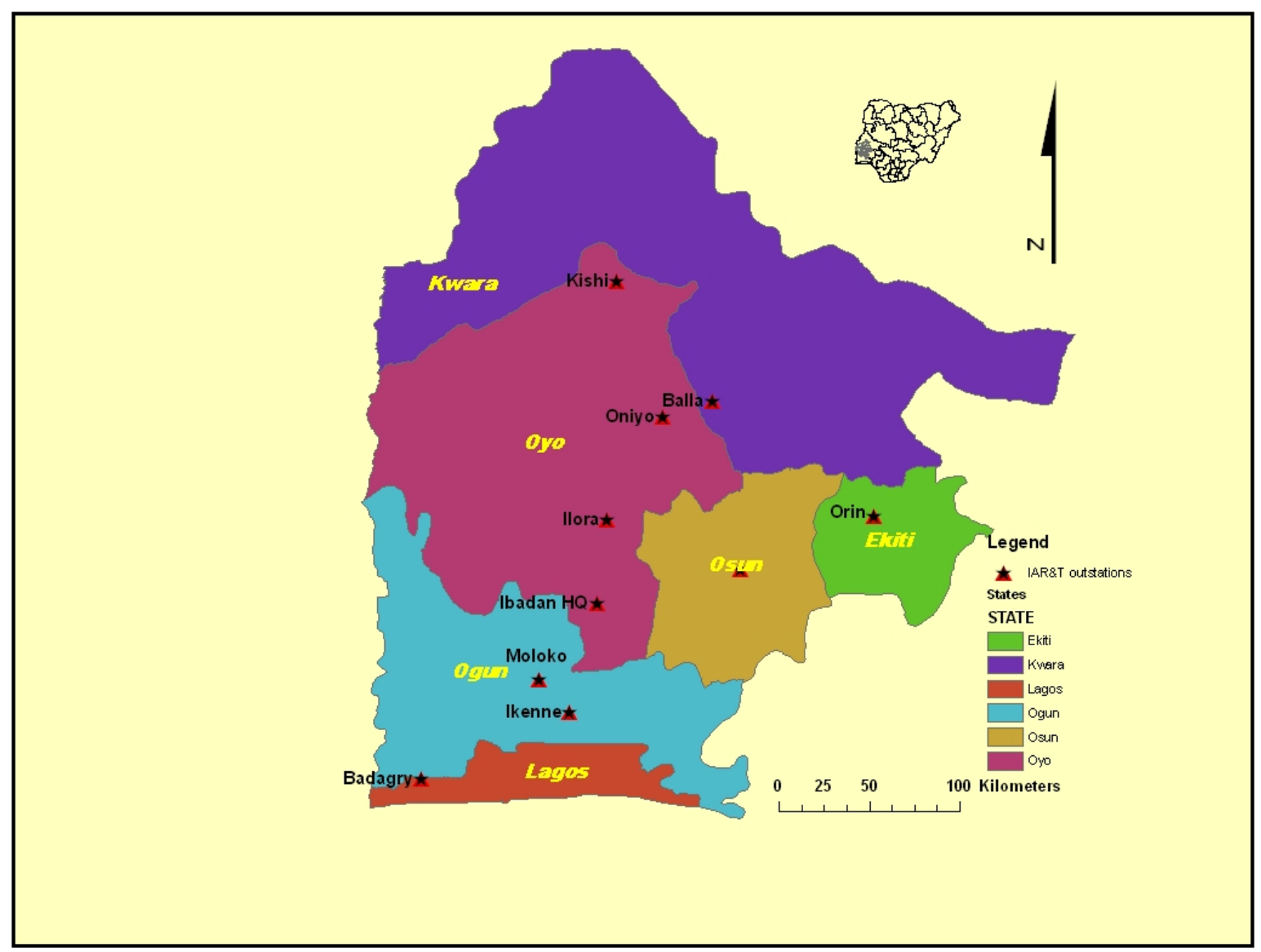

Figure 1. Map of South Western Nigeria showing the outstation of the Institute of Agricultural Research and Training, Ibadan. 


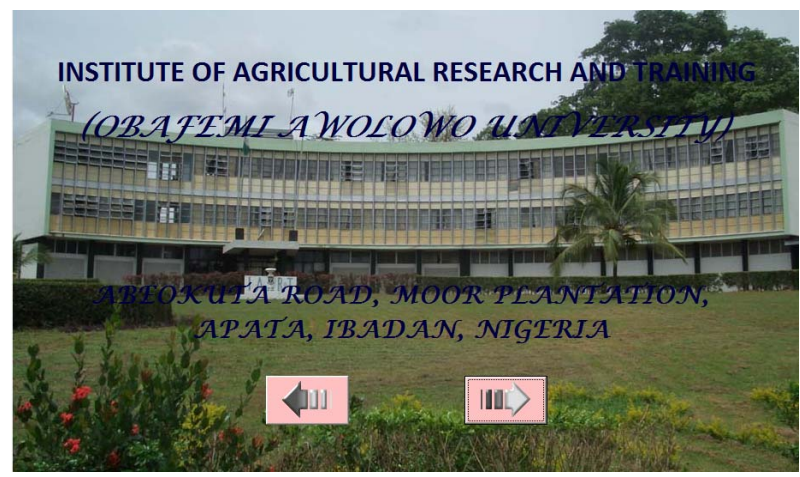

Figure 2. Splash screen of the information system.

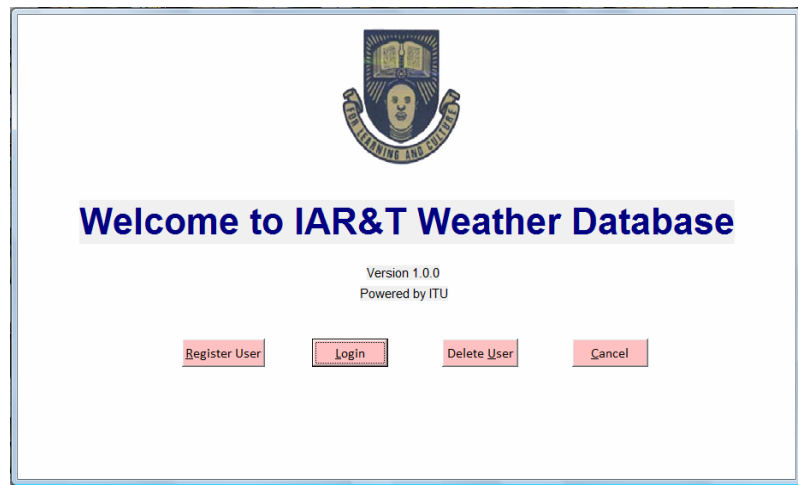

Figure 3. Welcome interface of the information system.

register as a new user, log in (if already registered) or cancel the current step. The fourth option enables a user to be removed from the list of the database users.

\subsection{Registration Interface}

Here, a new user is allowed to register to enable him/her query the database (Figure 4). The data required for registration are the username and password. Users, after registration, can only query the database; he/she is not permitted to alter the content of the database. This is the main criterion for the use of information system.

\subsection{Login Interface}

A user that has been registered would have to log in to the system with his/her username and password, which are case sensitive (Figure 5). When a user logged in, the program keeps track of his/her activities and allows the user timeless use of the database.

\subsection{Main Menu}

When a user is successfully logged in, he/she is led to the Main Menu of the information system (Figure 6). The options on this interface are weather database, longitude

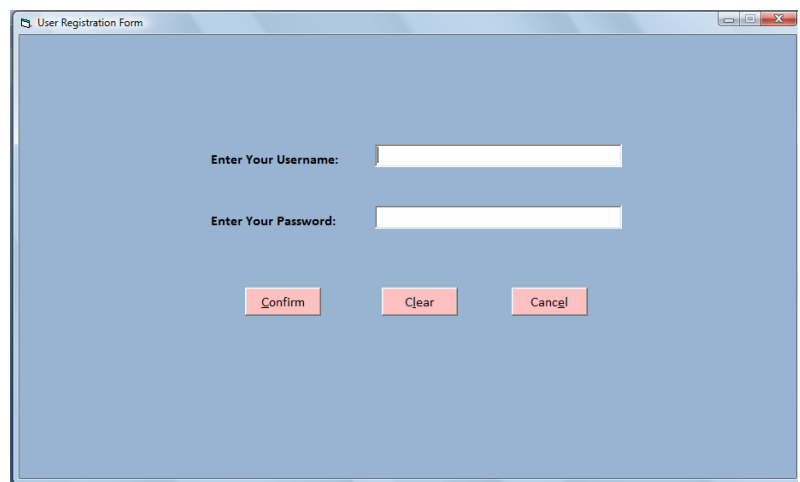

Figure 4. Registration interface of the information system.

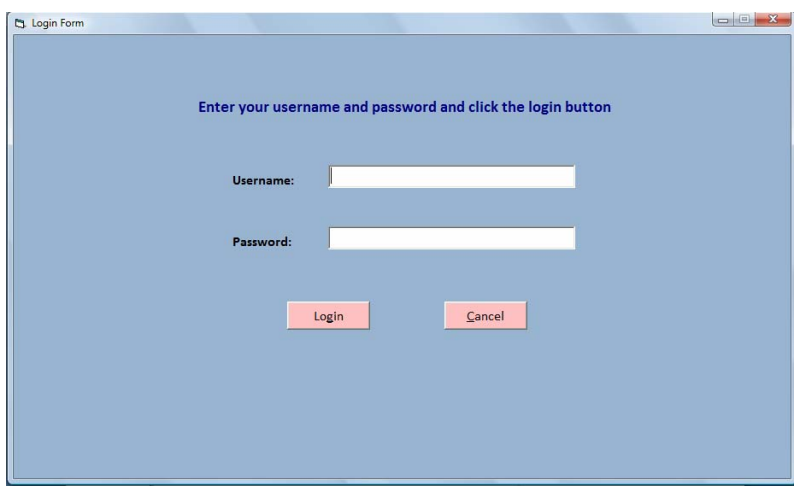

Figure 5. Login interface of the information system.

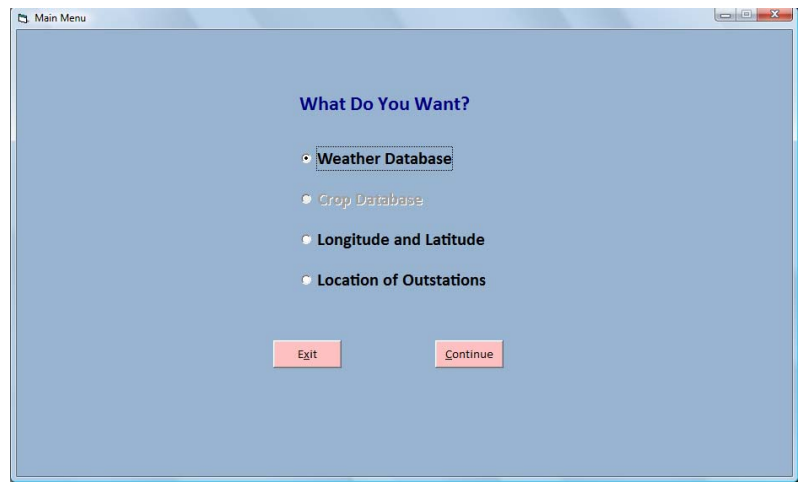

Figure 6. Main menu of the information system.

and latitude and location of outstations. Each of these menus links to the list of outstations. Weather database option is the platform which provides access to the rainfall data of all stations. The Latitude and latitude option gives the geographical position of the Institute's outstations on satellite.

Query regarding this option is executed by dynamically scouring the database to give the longitude and latitude of the inquired outstation. The last option, location of outstations, provides access to the map of south western Nigeria as well as other outstations of the Institute. This is done via an interface containing standard 
elements such as buttons adapted to display the maps on the screen with options to print, copy or save the images into any location.

\subsection{Rainfall Query Interface}

On the rainfall query interface (Figure 7), users can query the database for rainfall record of an outstation for a particular day or several consecutive days (range of records). For a range of records, users could choose to perform required calculations, such as the mean and variance, only (Figure 8) or to display the records as well as the mean and variance (Figure 9).

\section{Discussion and Conclusion}

A new technique for the data base of the South west Nigeria have been developed with the goal of providing a good source of weather data for the region. The data base evolved composed of rainfall data from stations which cut across different regions or state of the South west Nigeria. The database is a non web-based unlike in the [1] due to the challenges of web hosting but similar to [2] and [9] for Idah, in USAE. Also, the program can periodically be updated for efficiency as well as be backed up for safe keep. The program can serve as source of data for various degree of weather and weather related studies. Verification results showed that the data base

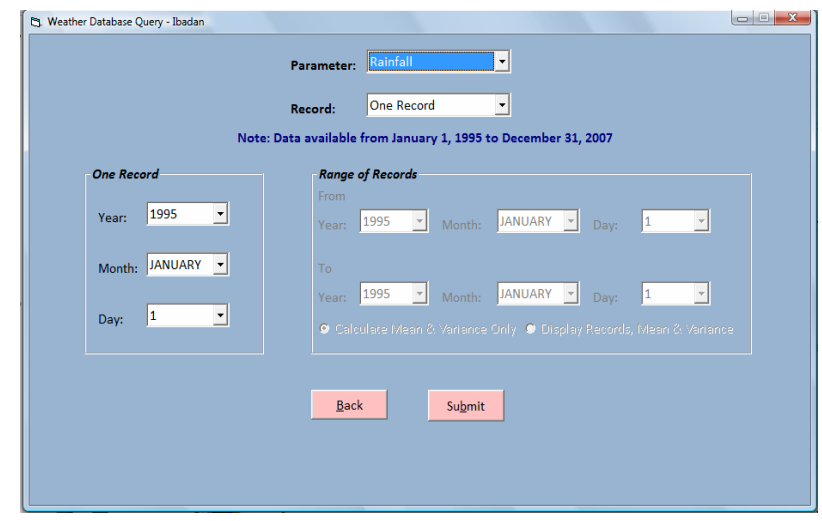

Figure 7. Rainfall query interface.

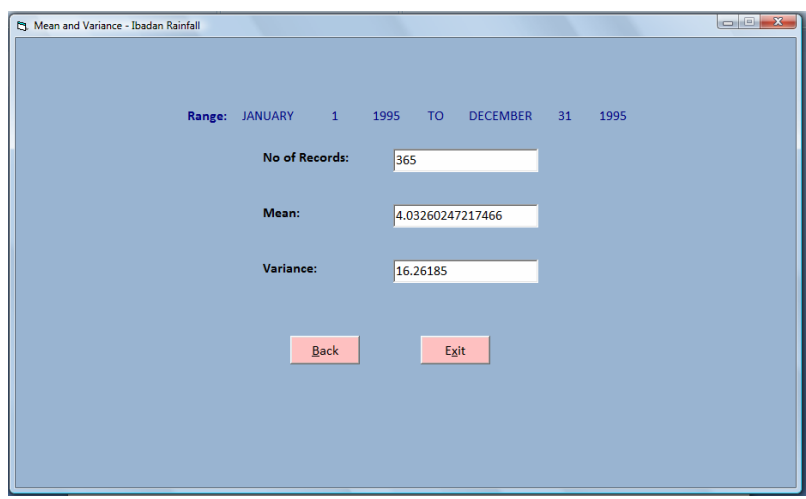

Figure 8. Query result showing the number of records, mean and variance.

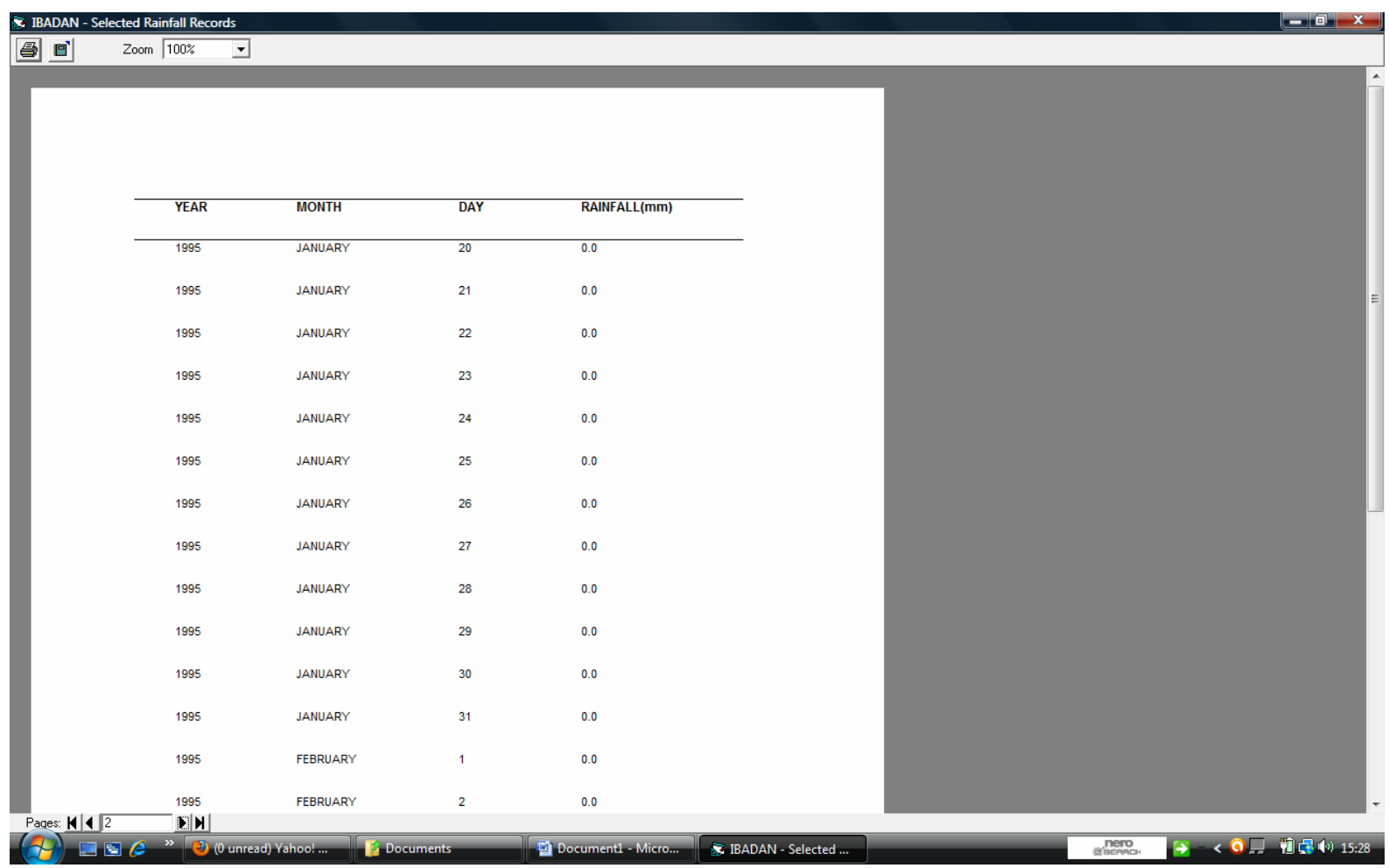

Figure 9. Query result showing a range of records. 
record is the same with the records on paper showing that the database as a source of data is reliable and can be used for any purposes with the observation of research ethics.

\section{References}

[1] Wikipedia Database. http://en.wikipedia.org/wiki/Databaseaccessedon19-07-2 $\underline{010}$

[2] C. L. Hanson, "Long-Term Precipitation Database, Reynolds Creek Experimental Watershed, Idaho, United States," Water Resources Research, Vol. 37, No. 11, 2001, pp. 2831-2834. doi:10.1029/2001WR000415

[3] J. Galindo, A. Urrutia and M. Piattini, "Fuzzy Databases: Modeling, Design and Implementation (FSQL Guide)," Idea Group Publishing, Hershey, 2006, p. 458.
[4] Webopodia Database, 2010 http://www.webopedia.com/TERM/D/database.html

[5] T. Connolly and B. Carolyn, "Database Systems," Harlow, New York, 2002, p. 356.

[6] M. Hermann and R. Bruno, Available Data at the Arctic Precipitation Data Archive APDA, 2010, http://gpcc.dwd.de

[7] D. D. Bosch, J. M. Sheridan and L. K. Marshall, "Precipitation, Soil Moisture, and Climate Database, Little River Experimental Watershed, Georgia, United States," Water Resource Research, Vol. 43, , 2007, p. 56.

[8] W. Zucchini, N. Oleg and G. Kratz, “A Web-Based Rainfall Atlas for Southern Africa,” 2010 http://134.76.173.220/rainfall/index.html

[9] P. Beynon-Davies, "Database Systems," 3rd Edition, Palgrave, Houndmills, Basingstoke, 2004, p. 578. 